\title{
Correction to "Dust and sea salt variability in central East Antarctica (Dome C) over the last 45 kyrs and its implications for southern high-latitude climate" by R. Röthlisberger et al.
}

Received 16 January 2003; published 6 March 2003.

INDEX TERMS: 3344 Meteorology and Atmospheric Dynamics: Paleoclimatology; 0368 Atmospheric Composition and Structure: Troposphere-constituent transport and chemistry; 1620 Global Change: Climate dynamics (3309); 9310 Information Related to Geographic Region: Antarctica; 9900 Corrections. Citation: Röthlisberger, R., R. Mulvaney, E. W. Wolff, M. A. Hutterli, M. Bigler, S. Sommer, and J. Jouzel, Correction to "Dust and sea salt variability in central East Antarctica (Dome C) over the last $45 \mathrm{kyrs}$ and its implications for southern high-latitude climate"' by R. Röthlisberger et al., Geophys. Res. Lett., 30(5), 1216, doi:10.1029/2003GL016936, 2003.

[1] In the paper "Dust and sea salt variability in central East Antarctica (Dome C) over the last 45 kyrs and its implications for southern high-latitude climate" by Regine Röthlisberger, Robert Mulvaney, Eric W. Wolff, Manuel A. Hutterli, Matthias Bigler, Stefan Sommer, and Jean Jouzel [Geophys. Res. Lett., 29(20), 1963, doi:10.1029/ 2002GL015186, 2002], an incorrect version of Figure 1 was published. The correct Figure 1 and its caption appear below.

[2] The following reference appeared incorrectly. The correct version follows: Delmonte, B., J. R. Petit, and V. Maggi, Glacial to Holocene implications of the new 27,000year dust record from the EPICA Dome C (East Antarctica) ice core, Clim. Dyn., 18(8), 647-660, doi: 10.1007/s00382001-0193-9, 2002. Consequently, the correct citations for this reference appear below.
[3] In paragraph [7], the last sentence should read as follows: The changes seen in nss- $\mathrm{Ca}^{2+}$ concentrations agree with insoluble dust measurements [Delmonte et al., 2002], with particle number and mass concentration changing by a factor of 50 from the LGM to the Holocene and a factor of 2 from the ACR to the Holocene.

[4] In paragraph [9], the fifth sentence should read as follows: These results are supported by dust particle measurements [Delmonte et al., 2002], which showed a slightly smaller particle mode and a smaller geometric standard deviation of the particle size distribution in the glacial than in the Holocene, indicative of a tendency to longer transport paths and less meridional transport. The sixth sentence should read as follows: On the other hand, based on GCM simulations Krinner and Genthon [2002] concluded that the dust transport from Patagonia to Dome C was faster during the LGM, in contrast to the studies by Lunt and Valdes [2001] and Delmonte et al. [2002].

[5] The following acknowledgment was incorrectly published. In paragraph [15], the first sentence should read as follows: Acknowledgments. This work is contribution No. 49 to the "European Project for Ice Coring in Antarctica" (EPICA), a joint ESF (European Science Foundation)/EC scientific programme, funded by the European Commission and national contributions from Belgium, Denmark, France, Germany, Italy, the Netherlands, Norway, Sweden, Switzerland, and the United Kingdom.

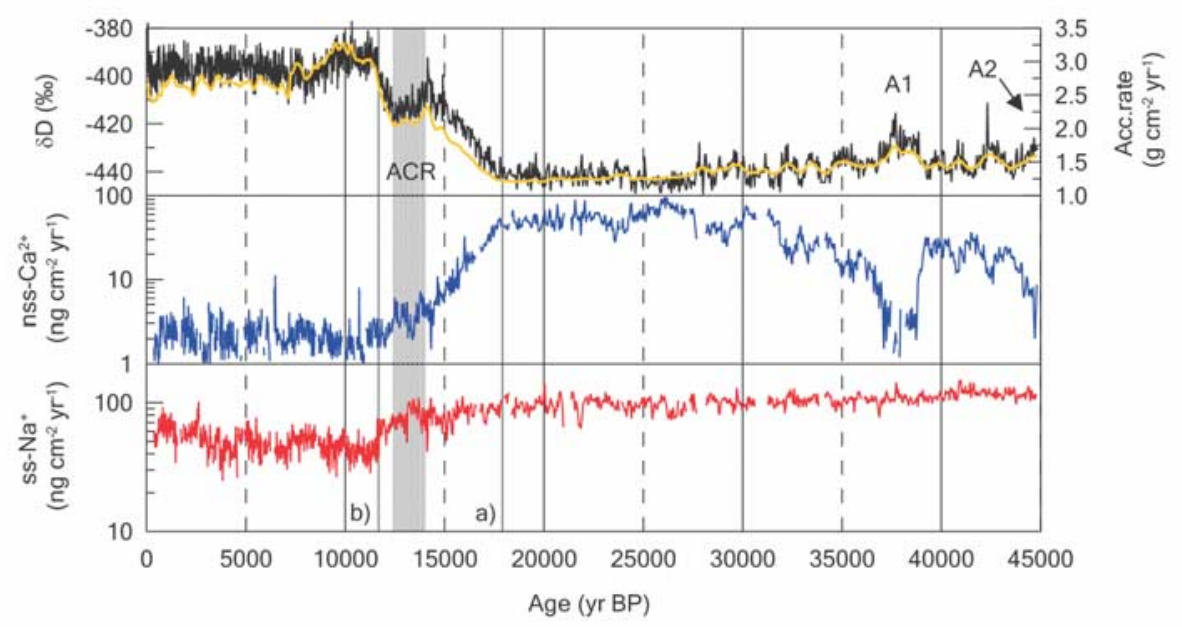

Figure 1. Fluxes of ss- $\mathrm{Na}^{+}$and nss-Ca ${ }^{2+}$, as well as the $\delta \mathrm{D}$ and the accumulation rate (yellow line, [Schwander et al., 2001]) from the top $780 \mathrm{~m}$ of the EPICA Dome $C$ deep ice core at $55 \mathrm{~cm}$ resolution. The vertical grey lines refer to the beginning (a) and the end (b) of the Transition, the shaded area corresponds to the Antarctic Cold Reversal (ACR). 